\title{
Infecção por leptospiras em ovinos e caracterização da resposta inflamatória renal ${ }^{1}$
}

\author{
Sônia Maria de Carvalho ${ }^{2}$ Larissa Maria Feitosa Gonçalves ${ }^{2}$ Nicodemos Alves de \\ Macedo $^{3}$ Hiro Goto ${ }^{4}$ Silvana Maria Medeiros de Sousa Silva ${ }^{3}$ Ana Lys Bezerra Barradas \\ Mineiro $^{2}$ Edite Hatsumi Yamashiro Kanashiro ${ }^{4}$ e Francisco Assis Lima Costa ${ }^{3 *}$
}

\begin{abstract}
Carvalho S.M., Gonçalves L.M.F., Macedo N.A., Goto H., Silva S.M.M.S., Mineiro A.L.B.B., Kanashiro E.H.Y. \& Costa F.A.L. 2011. [Leptospirosis Infection in Sheep and Characterization of the Renal Inflammatory Response.] Infecção por leptospiras em ovinos e caracterização da resposta inflamatória renal. Pesquisa Veterinária Brasileira 31(8):637-642. Departamento de Clínica e Cirurgia Veterinária, Centro de Ciências Agrárias, Universidade Federal do Piauí, Campus Socopo, Teresina, PI 64046-550, Brazil. E-mail: fassisle@gmail.com

Lepitospirosis is a serious worldwide distribution disease which affects man and other animals. The infection is generally asymptomatic in animals. In cases whose symptoms are present, symptoms are similar to other infections. In the present study serum samples from 119 sheep and their kidneys were collected during their slaughter in outdoor markets in the city of Teresina, Piauí, Brazil. The Microscopic Agglutination Test (MAT) obtained 34 positive serological samples for one or more Leptospira spp. serovar with occurrence rate of $28.6 \%$ of leptospiral antibodies. There were 23 cases of infection for a single serovar, and 11 cases with coagglutination for two or more serovars. Autumnalis had the highest occurrence $(29.4 \%)$ among the pathogenic serovars. The histopathological analysis of 36 kidney fragments revealed tubulo-interstitial alterations in $33(91.7 \%)$ positive animals. Tubular lesions were observed in $20(55.5 \%)$ positive animals. The Warthin Starry staning revealed the presence of Leptospira in 8 (22.20\%) of the 36 positive samples. The immunoperoxidase staining revealed the presence of Leptospira in $12(60 \%)$ of 20 positive samples. The inflammatory infiltrate in the positive animals was significantly more evident in the cortical-medullar and cortical regions than in the medullar region $(\mathrm{p}=0.000)$, however, there was no difference between positive and negative animals. The presence of hyaline casts in the proximal tubules was significantly higher in positive animals compared to the negative ones ( $p=0.0001$ ). Discrete lesion was observed in glomeruli. In conclusion, the results from this study showed that sheep which are positive for Leptospira present tubulo-intersticial renal lesions with the presence of Leptospira in the tubules, conferring to these animals the condition of asymptomatic carriers.

INDEX TERMS: Leptospirosis, serology, interstitial nephritis, sheep.
\end{abstract}

RESUMO.- As Leptospiroses são zoonoses graves de distribuição mundial que afetam o homem e outros animais. A infecção em animais, geralmente, é inaparente, ou os sintomas quando presentes são similares a outras infecções. Neste es-

\footnotetext{
${ }^{1}$ Recebido em 10 fevereiro de 2011.

Aceito para publicação em 24 de fevereiro de 2011.

Trabalho financiado pelo CNPq/PADCT e FAPEPI.

2 Doutoranda em Ciência Animal, Centro de Ciências Agrárias (CCA), Universidade Federal do Piauí (UFPI), Campus Socopo, Teresina, PI 64046-550, Brasil

${ }^{3}$ Departamento de Clínica e Cirurgia Veterinária, CCA-UFPI, Campus Socopo, Teresina, PI. *Autor para correspondência: fassisle@gmail.com

${ }^{4}$ Instituto de Medicina Tropical de São Paulo e Faculdade de Medicina, Universidade de São Paulo (USP), Av. Dr Enéas Carvalho Aguiar, 470, São Paulo, SP 05403-000, Brasil.
}

tudo foram colhidos soros de 119 ovinos e seus respectivos rins durante abate em feiras livres no município de Teresina-Piauí. Pela técnica de soroaglutinação microscópica (SAM) obtiveram-se 34 amostras sorológicas positivas para um ou mais sorovares de Leptospira spp., com taxa de ocorrência de 28,6\% de anticorpos anti-leptospiras, sendo 23 casos de infecção para um único sorovar e 11 com coaglutinações para dois ou mais sorovares. Dentre os sorovares patogênicos, o de maior ocorrência foi o Autumnalis $(29,4 \%)$. A análise histopatológica de 36 fragmentos de rins revelou alterações túbulo intersticiais em 33 (91,7\%) animais soro-reagentes. Lesões tubulares foram observadas em 20 (55,5\%) animais soro-reagentes. A presença de leptospiras, pela técnica de Warthin Starry, foi observada em $8(22,20 \%)$ amostras posi- 
tivas. Pela técnica de imunoperixidase, de 20 casos analisados, foi verificada a presença de leptospira em $12(60 \%)$ de 20 amostras positivas. Nos animais soro-reagentes, o infiltrado inflamatório foi significantemente mais evidente na região córtico-medular e cortical do que na região medular $(\mathrm{p}=0,000)$, mas não houve diferença entre animais soro-reagentes e soro não-reagentes. Cilindros hialinos nos túbulos proximais estavam presentes em quantidade significantemente maior nos animais soro-reagentes comparados aos não-reagentes $(p=0,0001)$. Em glomérulos, foi observada lesão discreta. Os resultados deste estudo mostram que ovinos soro-reagentes para leptospiras apresentam lesões renais túbulo intersticiais, com presença de leptospiras nos túbulos, o que confere a esses animais a condição de disseminadores da infecção.

TERMOS DE INDEXAÇÃO: Leptospirose, sorologia, nefrite intersticial, ovinos.

\section{INTRODUÇÃO}

Leptospiroses são doenças graves, que se manifestam de forma aguda e febril, ocorrendo no homem e em outros animais em todo o mundo (Faine et al. 1999, Juliano et al. 2000, Plank $\&$ Dean 2000). Animais que se recuperam da forma aguda podem adquirir a condição de portadores, nos quais leptospiras crescem e podem permanecer nos túbulos renais por dias ou anos (Faine et al. 1999). Nesses casos a doença não apresenta manifestações típicas e, geralmente, é inaparente. 0 diagnóstico depende de uma combinação de testes, envolvendo a demonstração de leptospiras por microscopia, isolamento por meio de cultivo, e teste sorológico com destaque para a soroaglutinação microscópica (SAM) por ser sorogrupo específica (Vasconcellos 2004).

Estudos sobre levantamentos sorológicos para infecção por leptospiras em ovinos no Brasil registraram os seguintes percentuais de soro-reagentes: 44,6\% (Langoni et al. 1995) e 8,6\% (Barbudo Filho et al. 1999) em São Paulo; 26,3\% em Pernambuco (Borba 2004); 10,28\% no Piauí (Costa et al. 2004); 34,26\% (Herrmann et al. 2004) e 20,9\% (Silva et al. 2007) no Rio Grande do Sul, e 13,7\% no Rio de Janeiro (Lilenbaum et al. 2009). Em outros países, os percentuais observados foram: $20 \%$ na Nova Zelândia (Blackmore et al. 1982); 1,7\% na Espanha (Leon-Vizcaino et al. 1987); 9,8\% na França (Trap \& Garin-Bastuji 1988); 42\% na Austrália (Ellis et al. 1994); 5,7\% no Chile (Zamora et al 1999); 6,1\% na Itália (Ciceroni et al. 2000); e 23,5\% na Nigéria (Agunloye 2002).

As leptospiras têm como órgão preferencial os rins, no qual provocam lesões severas e de onde são transportadas pela urina para contaminar o ambiente e serem transmitidas para o homem e outros animais (Levett 2001). A nefropatia causada pelas leptospiroses tem sido melhor estudada no homem (Sitprija et al. 1980).

Ovinos por serem animais de produção explorados, principalmente, nas regiões sul e nordeste do Brasil, têm importância econômica e social destacada nas economias regionais. $\mathrm{O}$ fato de as leptospiras se localizarem e se multiplicarem nos rins colocam em risco a sanidade de todo o rebanho e a saúde do homem, pois a doença é uma zoonose severa transmitida via contaminação ambiental pela urina de animais infectados (Levett 2001). Lesões renais túbulo-intersticiais são consideradas as alterações patológicas básicas da doença (Maxie 1993). A nefrite intersticial crônica (Oliveira et al. 2005) é caracterizada por infiltrado de linfócitos, plasmócitos (Yener \& Keles 2001, Saglam et al. 2003), macrófagos (Rossetti et al. 2004) e raros eosinófilos (Scanziani et al. 1989). Degeneração e necrose de células epiteliais envolvem primariamente os túbulos proximais (Ellis et al. 1984, Yener \& Keles 2001, Delbem et al. 2002, Saglam et al. 2003). Tais alterações manifestam-se, freqüentemente, por proteinúria e cilindros hialinos no lume dos túbulos (Saglam et al. 2003, Rossetti et al. 2004, Haanwinckel et al. 2004). A lesão túbulo-intersticial e a fibrose têm papel crítico na progressão da doença renal (Hughes 2000).

0 presente trabalho teve como objetivo verificar a ocorrência de aglutininas para leptospiras em ovinos, caracterizar a natureza e a extensão das lesões renais e avaliar se ovinos aparentemente sadios, abatidos para consumo, são portadores da infecção.

\section{MATERIAL E MÉTODOS}

Foram utilizados 119 ovinos de ambos os sexos, adultos, provenientes de diversos municípios do Estado do Piauí, inclusive de municípios localizados na região semi-árida, abatidos em feiras livres no município de Teresina, para consumo, no período de junho de 2003 a março de 2004.

As amostras de sangue foram coletadas da veia jugular em tubos de vácuo de $10 \mathrm{ml}$, sem anti-coagulante. No laboratório, o soro obtido foi armazenado a $-20^{\circ} \mathrm{C}$ até o processamento.

Para a pesquisa de aglutininas anti-leptospiras foi utilizada a prova de soroaglutinação microscópica (SAM), segundo as recomendações de Faine et al. (1999), contra 22 sorovares patogênicos e 2 saprófitas: Leptospira interrogans sorovares Australis, Bratislava, Autumnalis, Bataviae, Canicola, Sentot, Grippotyphosa, Hebdomadis, Copenhageni, Pomona, Pyrogenes, Wolffi e Hardjo (Hardjoprajitino); L. borgpetersenii sorovares Castellonis, Whitcombi, Tarassovi, Javanica e Hardjo (hardjo bovis); L. kirshneri sorovares Butembo e Cynopteri; L. inadai sorovar Icterohaemorrhagiae; $L$. noguchii sorovar Panama; L. santarosai sorovar Shermani; e $L$. biflexa sorovariedades Andamana e Patoc. As culturas foram mantidas durante 5 a 10 dias a $28^{\circ} \mathrm{C}$ em meio EMJH enriquecido com soro de coelho, inativado, estéril (Alves et al. 1996). Todos os soros foram testados inicialmente na diluição 1:100 para triagem. Foi considerado reagente o soro com no mínimo $50 \%$ de aglutinação. As amostras reagentes, na triagem, foram novamente examinadas em diluições crescentes, considerando-se como título do soro a recíproca da sua maior diluição a apresentar $50 \%$ de aglutinação. 0 sorovar registrado foi o que apresentou maior título. Quando o maior título foi apresentado para dois ou mais sorovares, o animal foi excluído da análise de ocorrência, mas não da casuística das alterações histopatológicas.

Imediatamente após o abate dos animais, foi realizada coleta de fragmentos de tecido renal, abrangendo a região cortical e medular de ambos os rins, que foram fixados em solução de DuboscqBrasil por 60 minutos e mantidos em formol neutro a $10 \%$, tamponado com fosfato, 0,01 M pH 7,4 (formol tamponado) até o processamento. Para o estudo das alterações renais foram utilizados fragmentos de rins de 36 animais soro reagentes, e de 10 animais não reagentes ao teste de SAM, como controle. Os fragmentos de rins, direito ou esquerdo, foram selecionados aleatoriamente por sorteio. 
Os fragmentos de rins fixados em formol tamponado foram processados seguindo técnicas de rotina e os cortes corados com hematoxilina-eosina (HE), ácido periódico de Schiff (PAS), tricrômico de Masson (TM), ácido periódico prata metanamine (PAMS), Warthin-Starry (WS) e Imunoperoxidase (IP).

As lâminas utilizadas nas reações de imunoistoquímica foram desparafinadas em xilol e em seguida os fragmentos hidratados em etanol (absoluto, 95\%, 90\%, 80\% e 70\%). O bloqueio da peroxidase endógena foi realizado com peróxido de hidrogênio $3 \%$ em metanol, por 30 minutos no escuro, após isso, foi realizada lavagem em tampão PBS 0,01 pH 7,2. 0 desmascaramento de antígeno foi realizado em forno Microondas (Sanyo, Brasil) potência 10, em solução de Tris Hcl pH 1,0, sucessivamente por 10 e 5 minutos, seguido de lavagem em PBS. As lâminas foram incubadas com anticorpo primário anti-leptospira produzido no Instituto de Medicina Tropical de São Paulo, diluído a 1:400 em PBS 0,01 "over night" em câmara úmida a $4^{\circ} \mathrm{C}$. A incubação com anticorpo secundário e a amplificação da reação foi realizada com o EnVision System (Dako Corporation, Carpinteria, CA, USA, código K4011) em câmara úmida, temperatura ambiente por 30 minutos. Na revelação utilizouse, 30mg 3,3 Diaminobenzidine tetrahydrochloride (DAB) em $100 \mathrm{ml}$ de PBS, $200 \mu$ l de Peróxido de Hidrogênio (Sigma Chemical, USA) a 30\%. Contracoloração com Hematoxilina de Harrys (Sigma Chemical, USA) por 30 segundos. Procedeu-se a desidratação e montagem com Entelan.

A intensidade das lesões foi classificada semi-quantitativamente, em escores, numa escala de 0 a 5 em que $0=$ normal, $1=$ mínima, 2 = média, 3 = moderada, $4=$ moderadamente severa, e $5=$ severa (Pirani, 1993).

Os dados semi-quantitativos foram analisados por testes não paramétricos: a) teste exato de Fisher, b) teste U de Mann-Whitney para comparação entre dois grupos e, c) teste de Kruskal-Wallis para análise de variância. Os casos com diferença significante pelo último teste, foram analisados pelos testes de Student-NewmanKeuls (SNK) ou Dunn para comparação múltipla de grupos (Bioestat, 5.0). Adotou-se o nivel de significância de $p<0,05$.

\section{RESULTADOS E DISCUSSÃO}

De 119 animais examinados pela prova de SAM, 36 reagiram para um ou mais sorovares de Leptospira interrogans. Desses, dois animais apresentaram reação de soroaglutinação com títulos iguais e foram excluídos da análise de ocorrência, mas não da casuística do estudo histopatológico. Portanto, apenas 34 animais reagentes foram considerados para o estudo sorológico e 36 para casuística da análise histopatológica.

Neste contexto pode-se assegurar que a taxa de ocorrência de anticorpos anti-leptospiras foi de 28,6\%. A resposta sorológica observada, provavelmente, reflete exposição natural à infecção, porque a vacinação de ovinos não é praticada no Estado do Piauí.

Dentre os animais soro reagentes, 23 reagiram para um único sorovar, 7 reagiram para dois sorovares, 2 para três e 2 para cinco. Nesses casos, considerou-se como sorovar mais provável aquele cuja reação apresentou maior título.

Os resultados sorológicos indicaram maior importância para os sorovares patogênicos Autumnalis (29,4\%), Castellonis $(17,6 \%)$, Grippothyphosa (5,9\%), Pyrogenes $(2,9 \%)$, Butembo (2,9\%) e Pomona (2,9\%), presentes em 21 animais em infecção única e múltipla, enquanto o único sorovar saprófita (Patoc) esteve presente em 13 animais (38,2\%) em infecção única. Outros sorovares reagentes foram: Bratislava, Australis, Hebdomadis, Hardjo (hardjo prajitino), Sentot e
Cynopteri. Resultados percentualmente superiores ou inferiores, foram encontrados em Langoni et al. (1995), Barbudo Filho et al. (1999), Ciceroni et al. (2000), Agunloye (2002) e Herrmann et al. (2004), revelando que o diagnóstico de sorovares infectantes para ovinos varia, também, na dependência da região. A ocorrência de infecção por leptospiras na região semi-árida do Estado do Piauí, sugere que a infecção dos animais acontece nos poucos locais de retenção de águas pluviais (aguadas, barreiros), contaminadas por urina de outros animais, inclusive roedores silvestres. Outra possibilidade de infecção dos ovinos é o estreito convívio com bovinos e outras espécies animais como caprinos, suínos, etc., consorciados em criações mistas (Langoni et al. 1995), como ocorre no semi-árido piauiense. Cabe destacar, que o sorovar autumnalis, de maior prevalência nesta pesquisa, é frequentemente encontrado em cães no nordeste (Alves et al. 2000, Batista et al. 2004), espécie que sempre está presente em áreas de criação de animais no nordeste, incluindo ovinos.

Para o estudo das alterações renais foram utilizados fragmentos de rins de 36 animais soro- reagentes e de 10 animais não-reagentes ao teste de SAM, como controle.

Nos 36 animais soro-reagentes e nos 10 animais não reagentes, incluídos na casuística para análise das lesões renais, não foram observadas alterações macroscópicas. Em 33 animais $(71,74 \%)$ foram observadas alterações ao exame microscópico. Nefrite intersticial foi observada em 26 animais sororeagentes, caracterizada pela presença de linfócitos, macrófagos, fibroblastos, plasmócitos e raros neutrófilos (Fig.1). A lesão foi encontrada, principalmente, na região córtico-medular, mas também na região cortical e medular, de distribuição focal perivascular, periglomerular e peritubular, com intensidade variando de mínima a moderada. 0 infiltrado inflamatório intersticial na região córtico-medular e cortical foi mais evidente que na região medular ( $p=0,000$, Teste de Kruskal Wallis e Dunn) nos animais soro-regentes e, em alguns casos, foi constatada, também, a presença de fibrose intersticial pela coloração de TM (Fig.1). Infiltrado inflamatório intersticial estava presente em ambos os grupos sem diferença significante (Quadro 1). Lesões tubulares foram melhor observadas pelas colorações de PAS e PAMS em 20 (55,55\%) animais soro-reagentes, consistindo de atrofia tubular, necrose de membrana basal tubular, degeneração hialina goticular e degeneração pigmentar. Provavelmente, a presença destas alterações seja decorrente da invasão bacteriana, da presença de antígenos de membrana e da infiltração celular (Barnett et al. 1999). Cilindros hialinos (Fig.2) foram as alterações tubulares mais freqüentes, presentes em 11 animais soro-reagentes o que diferia significantemente em relação aos animais não-reagentes $(p=0,0001$, Teste U de Mann Whitney) demonstrando que estava ocorrendo desequilíbrio no processo de filtração e reabsorção de proteína, mas, ainda, sem manifestação de alteração da função renal. Vasculite foi observada em cinco animais. Esta alteração é citada como parte do quadro patológico da leptospirose em sua fase aguda, portanto, normalmente não é observada na fase crônica (Plank \& Dean 2000, Levett 2001, Sitprija et al. 2003). Entretanto, no presente trabalho, vasculite estava presente nos animais que apresentaram títulos sorológicos inferiores ou iguais a 400 e quadro anátomo-patológico típico de animais na fase crônica da infecção. 


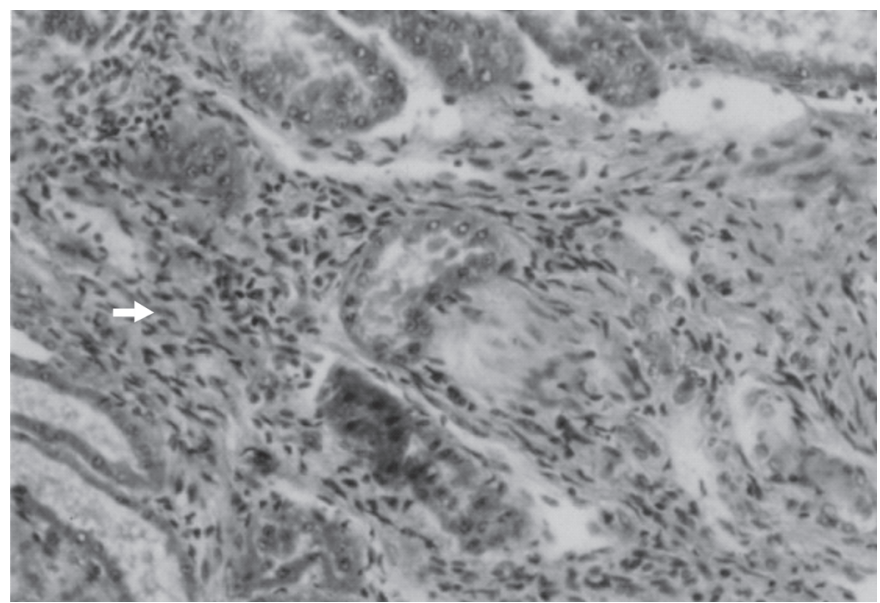

Fig.1. Infiltrado inflamatório caracterizado por linfócitos, macrófagos, fibroblastos (seta), plasmócitos e raros neutrófilos e fibrose, no rim de ovino infectado naturalmente por Leptospira spp. Masson, 140x.

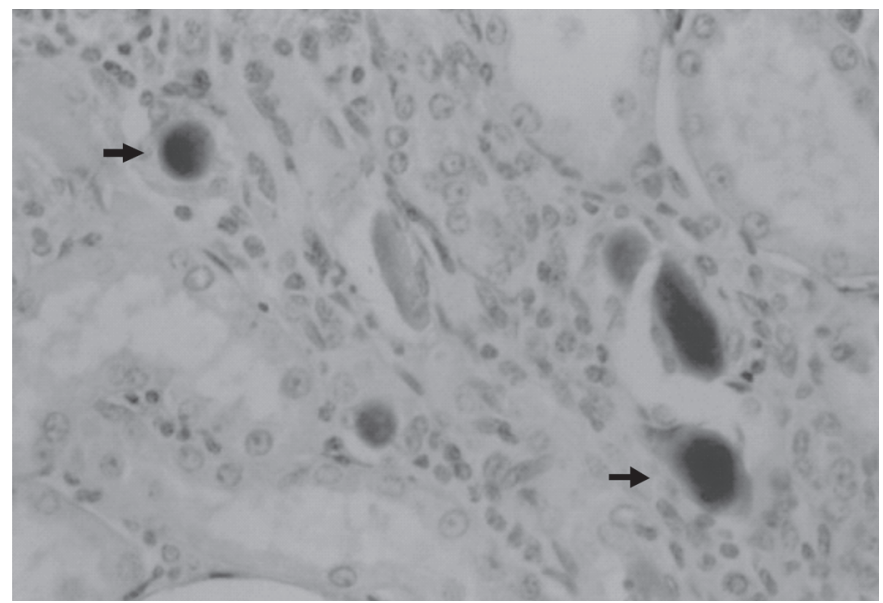

Fig.2. Cilindros hialinos (setas) em túbulos renais, em ovino infectado naturalmente por Leptospira spp.. PAS, 140x.

Em 8 ovinos (22,20\%) de um total de 36 soro-reagentes, leptospiras foram detectadas no lume dos túbulos proximais por meio da técnica de Warthin-Starry. Nos 10 ovinos não reagentes, nenhuma leptospira foi observada. Entretanto, a aplicação do teste exato de Fisher revelou que não havia diferença significante entre os dois grupos (Quadro 1). As leptospiras apresentavam-se agrupadas em massas de cor enegrecida aderidas à superfície das células epiteliais tubulares (Fig.3) e livres no lume, o que sugere que ovinos infectados naturalmente por sorovares de Leptospira spp., sem manifestação clínica da doença, podem transportar o microrganismo na urina e, assim, constituírem-se em reservatórios assintomáticos capazes de contaminar o ambiente, o homem e outros animais, como é observado para outras espécies (Faine 1999). A nefrite intersticial nesses animais era moderada e a reação de soroaglutinação variou de 100 a 3.200 . 0 percentual de leptospiras encontrado $(22,20 \%)$ foi inferior ao observado por Scanziani et al. (1989) em suínos, Yener \& Keles (2001) em bovinos, Rossetti et al. (2004) em camundongos e superior ao observado por Saglam et al. (2003) em bovinos.

A detecção de antígeno e de leptospiras por imunoistoquímica foi realizada em 20 animais. Em todos eles havia presença de antígeno, mas Leptospira sp. foi detectada em so-
Quadro 1. Relação entre sorologia, alterações histopatológicas e detecção de Leptospira spp. pela técnica de Warthin-Starry em ovinos no Estado do Piauí

\begin{tabular}{|c|c|c|c|}
\hline $\begin{array}{c}\text { Caso } \\
\text { n. }\end{array}$ & SAM & $\begin{array}{l}\text { Alt. histo- } \\
\text { patológicas }^{\text {a }}\end{array}$ & $\begin{array}{l}\text { Warthin- } \\
\text { Starry }^{b}\end{array}$ \\
\hline 1 & - & + & - \\
\hline 2 & - & + & - \\
\hline 3 & - & + & - \\
\hline 4 & - & - & - \\
\hline 5 & - & + & - \\
\hline 6 & - & + & - \\
\hline 7 & - & + & - \\
\hline 8 & - & + & - \\
\hline 9 & - & + & - \\
\hline 10 & - & + & - \\
\hline 11 & 400 & + & - \\
\hline 12 & 200 & + & + \\
\hline 13 & 400 & + & + \\
\hline 14 & 100 & + & - \\
\hline 15 & 400 & + & - \\
\hline 16 & 400 & + & - \\
\hline 17 & 400 & + & - \\
\hline 18 & 400 & + & - \\
\hline 19 & 400 & + & - \\
\hline 20 & 100 & + & - \\
\hline 21 & 200 & + & + \\
\hline 22 & 200 & + & - \\
\hline 23 & 100 & + & - \\
\hline 24 & 100 & + & - \\
\hline 25 & 100 & + & - \\
\hline 26 & 200 & + & - \\
\hline 27 & 100 & + & - \\
\hline 28 & 100 & + & - \\
\hline 29 & 3200 & + & - \\
\hline 30 & 100 & + & - \\
\hline 31 & 1600 & - & - \\
\hline 32 & 800 & + & - \\
\hline 33 & 200 & + & + \\
\hline 34 & 100 & - & - \\
\hline 35 & 400 & + & + \\
\hline 36 & 100 & + & - \\
\hline 37 & 200 & + & + \\
\hline 38 & 100 & + & - \\
\hline 39 & 200 & + & - \\
\hline 40 & 200 & + & - \\
\hline 41 & 800 & + & - \\
\hline 42 & 400 & + & + \\
\hline 43 & 200 & + & - \\
\hline 44 & 400 & - & - \\
\hline 45 & 200 & + & - \\
\hline 46 & 100 & + & + \\
\hline
\end{tabular}

${ }^{a}$ Não houve diferença significante entre os animais reagentes e não-reagentes ( $p>0,05$, Teste U de Mann Whitney); ${ }^{b}$ Não houve diferença significante entre os animais reagente e não-reagentes ( $p>0,05$, Teste exato de Fisher). (+) Presença; (-) ausência.

mente $12(60 \%)$ animais. Em rim de bovinos, Saglam et al. (2003) detectaram percentual inferiror $(41,0 \%)$ de leptospiras. Antígeno foi observado no endotélio de vasos intersticiais, no citoplasma de células epiteliais tubulares, na cápsula de Bowman e nos capilares glomerulares. Leptospiras foram visualizadas livres no lúmen dos túbulos renais e na forma de agregados aderidas às células epiteliais tubulares (Fig.4). Dentre os 12 animais com presença de Leptospira sp, 8 eram sororeagentes ao sorovar Autumnalis e 8 apresentavam nefrite intersticial, revelando, desse modo, que a técnica de imunoistoquímica pode detectar mais leptospiras que a técnica de Warthin Starry, como observado por Scanziani et al. 


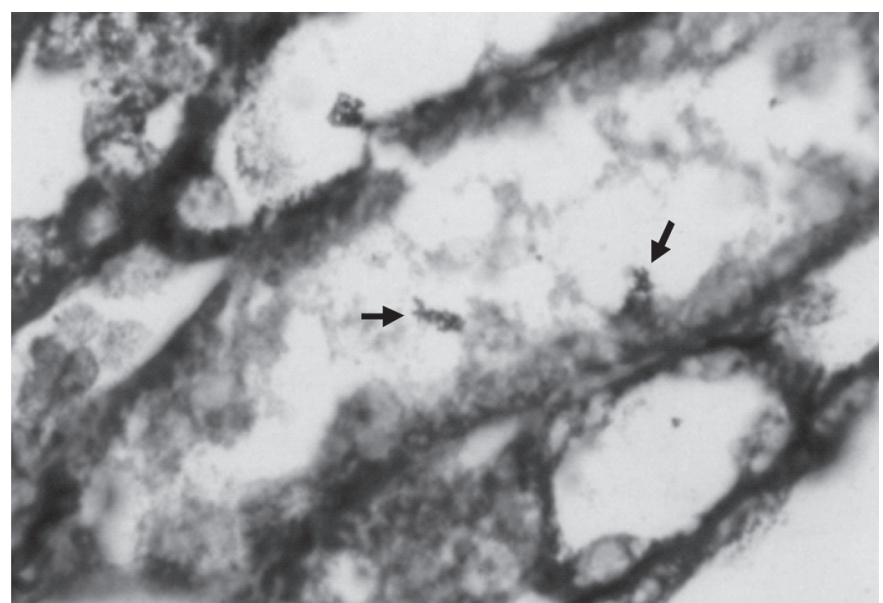

Fig.3. Presença de leptospiras (setas) aderidas às células epiteliais tubulares, em forma de aglomerado, no rim de ovino naturalmente infectado por Leptospira spp. Warthin Starry, 350x.

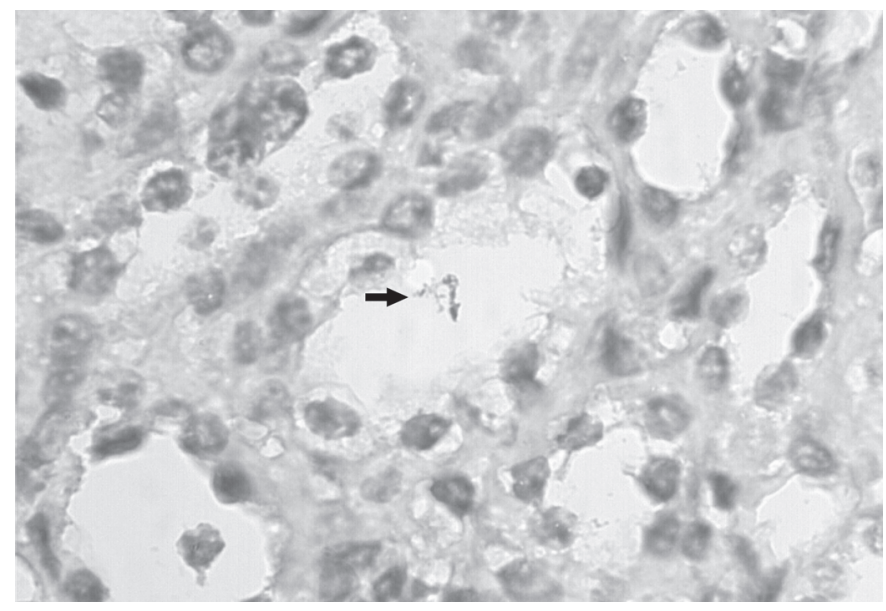

Fig.4. Presença de leptospiras (setas) no lume de túbulo renal, em forma de aglomerado, em ovino naturalmente infectado por Leptospira spp. Imunoperoxidase, 350x.

(1989), Yener \& Keles (2001), Silva et al. (2005) e Saglam et al. (2008).

As lesões glomerulares foram discretas, como registrado por De Brito et al. (1965) e Sitprija et al. (1980), mas a hipercelularidade e a lobulação do tufo glomerular chamaram a atenção. A coloração de PAMS não revelou anormalidade da membrana basal tubular.

Como observado no presente estudo, o local preferencial de lesão renal na leptospirose é o espaço túbulo-intersticial, com maior evidência de comprometimento dos túbulos proximais (Sitprija et al. 1980, Barnett et al. 1999), onde as leptospiras aderem e liberam toxinas, incluindo produtos da lise do microrganismo, que danificam as células epiteliais tubulares (Ferreira Alves et al. 1987). Essas alterações demonstram que as lesões renais túbulo-intersticiais são as alterações patológicas básicas da leptospirose (Maxie 1993).

0 processo inflamatório renal observado foi classificado como crônico, pois foi caracterizado pela presença de macrófagos, linfócitos, plasmócitos e fibrose intersticial, sem evidência de edema. Aliás, títulos de anticorpos anti-leptospira de 100 a 400 podem caracterizar a infecção na fase crônica (Ellis 1994, Ciceroni et al. 2000), como observado neste es- tudo. Ao lado disso, sabe-se que leptospiras se localizam nos rins após o estágio agudo inicial (Marinho et al. 2003).

Alterações renais, de intensidade mínima, foram observadas em 9 dos 10 animais sorologicamente não-reagentes, e cilindros hialinos estavam presentes apenas em animais soro-reagentes. Em suínos abatidos no Paraná foram encontrados resultados semelhantes (Delbem et al. 2002). Cabe destacar que embora não se tivesse controle de outras doenças, a nefrite intersticial observada nos animais soro-reagentes, provavelmente, estava associada á infecção por leptospiras, pois havia presença de leptospiras no lume de túbulos renais e havia cilindros hialinos, o que não foi observado nos animais não-reagentes.

Os resultados deste estudo demonstraram que ovinos do estado do Piauí, clinicamente sadios e destinados ao abate, estão infectados por Leptospira spp. 0 sorovar de maior ocorrência foi o Autumnalis. Os animais infectados apresentaram lesões renais túbulo-intersticiais, com presença da bactéria nos túbulos, o que confere aos mesmos a condição de portadores assintomáticos.

Agradecimento.- Ao CNPq/PADCT e à Fundação de Amparo à Pesquisa do Estado do Piauí (FAPEPI), pelo suporte financeiro.

\section{REFERÊNCIAS}

Agunloye C.A. 2002. Leptospiral agglutinating antibodies in sheep and goats in South-West Nigéria. Israel J. Vet. Med. 57:28-30.

Alves J.C., Andrade J.S.L., Vasconcellos S.A., Morais Z.M., Azevedo S.S. \& Santos F.A. 2000. Avaliação dos níveis de aglutininas anti-leptospiras em cães no município de Patos-PB, Brasil. Revta Bras. Cienc. Vet. 7:17-21.

Alves C.J., Vasconcellos S.A., Camargo C.R.A. \& Morais Z.M. 1996. Influência de Fatores Ambientais na proporção de caprinos soro-reagentes para a leptospirose em cinco centros de criação do Estado da Paraíba, Brasil. Arqs Inst. Biológico, São Paulo, 63:11-18.

Barbudo-Filho J., Girio R.J.S., Mathias L.A., Oliveira A.V. \& Marinho M. 1999. Pesquisa de anticorpos contra Leptospira interrogans em soros de ovinos do Estado de São Paulo. Avaliação do sorotipo jequitaia de Leptospira biflexa como antígeno de triagem sorológica. Ars Vet. 15:26-32.

Barnett J.K., Barnett D., Bolin C.A., Summers T.A., Wagar E.A., Cheville N.F., Hartskeerl R.A. \& Haake D.A. 1999. Expression and distribution of leptospiral outer membrane components during renal infection of hamsters. Infect. Immunol. 67:853-861.

Batista C.S.A., Azevedo S.S., Alves C.J., Vasconcellos S.A., Morais Z.M., Clementino I.J., Lima F.S. \& Araújo Neto J.O. 2004. Soroprevalência e fatores de risco para a leptospirose em cães de Campina Grande, Paraíba. Arq. Bras. Med. Vet. Zootec. 5(Supl.2):179-185.

Blackmore D.K., Bahaman A.R. \& Marshall R.B. 1982. The epidemiological interpretation of serological responses to leptospiral serovars in sheep. N. Z. Vet. J. 30:38-42.

Borba M.A. 2004. Estudo soroepidemiológico da leptospirose em caprinos e ovinos do Estado do Pernambuco. Dissertação de Mestrado em Ciências Veterinárias, Programa de Pós-Graduação em Ciência Veterinária, Universidade Federal Rural de Pernambuco, Recife. 70p.

Ciceroni L., Lombardo D., Pinto A., Ciarrocchi S. \& Simeoni J. 2000. Prevalence of antibodies to Leptospira serovars in sheep and goats in Alto Adige, South Tyrol. J. Vet. Med. B 47:217-223.

Costa G.S., Mineiro A.L.B.B. \& Macedo N.A. 2004. Anticorpos anti-leptospiras em soros de ovinos da microrregião de Teresina, PI. Anais eletrôni$\cos 31^{\circ}$ Conbravet, São Luís, MA.

De Brito T., Freymüller E., Penna D.O., Santos H.S., Almeida S.S., Galvão P.A.A. \& Pereira V.G. 1965. Electron microscopy of the biopsied kidney in human leptospirosis. Am. J. Trop. Med. Hyg. 14:397-403.

Delbem A.C.B., Freitas J.C., Bracarense A.P.F.R.L., Müller E.E. \& Oliveira R.C. 
2002. Leptospirosis in slaughtered sows: Serological and histopathological investigation. Braz. J. Microbiol. 33:174-177.

Ellis G.R., Partington D.L., Hindmarsh M. \& Barton M.D. 1994. Seroprevalence to Leptospira interrogans serovar hadjo in merino stud rams in South Austrália. Aust. Vet. J. 71:203-206.

Ellis T.M., Hustas L., Robertson G.M. \& Mayberry C. 1984. Kidney disease of sheep, associated with infection by leptospires of the sejroe serogroup. Aust. Vet. J. 61:304-305.

Ellis W.A. 1994. Leptospirosis as a cause of reproductive failure. Vet. Clin. North Am., Food Anim. Pract. 10:463-478.

Faine S., Adler B., Bolin C. \& Perolat P. 1999. Leptospira and Leptospirosis. $2^{\text {nd }}$ ed. Armadale, Australia. 272p.

Ferreira Alves V.A., Vianna M.R., Yasuda P.H. \& De Brito T. 1987. Detection of leptospiral antigen in the human liver and kidney using an immunoperoxidase staining procedure. J. Pathol. 151:125-131.

Haanwinckel M.C.S., Megid J. \& Souza L.C. 2004. Avaliação da prova de imunoperoxidase como recurso diagnóstico na leptospirose animal. Arqs Inst. Biológico, São Paulo, 71:293-301.

Herrmann G.P., Lage A. P., Moreira E.C., Haddad J.P.A., Resende J.R., Rodrigues R.O. \& Leite R.C. 2004. Soroprevalência de aglutininas anti-leptospiras spp em ovinos nas mesorregiões Sudeste e Sudoeste do Estado do Rio Grande do Sul, Brasil. Ciência Rural 34:443-448.

Hughes J. 2000. Apoptosis in tubulointerstitial renal diseases. Nephrol. Dial. Transplant 15(Suppl):55-57.

Juliano R.S., Chaves N.S.T., Santos C.A., Ramos L.S., Santos H.Q., Meireles L.R., Gottschalk S. \& Corrêa Filho R.A.C. 2000. Prevalência e aspectos epidemiológicos da leptospirose bovina em rebanho leiteiro na microrregião de Goiânia, GO. Ciência Rural 30:857-862.

Langoni H., Marinho M., BaldiniS., Silva A.V., Cabral K.G. \& Silva E.D. 1995. Pesquisa de aglutininas antileptospiras em soros de ovinos no Estado de São Paulo, Brasil, utilizando provas de macroaglutinação em placa e soroaglutinação microscópica. Revta Bras. Med. Vet. 17:264-268.

Leon-Vizcaino L., Mendoza M.H. \& Garrido F. 1987. Incidence of abortions caused by leptospirosis in sheep and goats in spain. Comp. Immunol. Microbiol. Infect. Dis. 10:149-153.

Levett P.N. 2001. Leptospirosis. Clin. Microbiol. Rev. 14:296-326.

Lilenbaum W., Varges R., Ristow P., Cortez A., Souza S.O., Richtzenhain L.J. \& Vasconcellos S.A. 2009. Identification of Leptospira spp. carriers among seroreactive goats and sheep by polymerase chain reaction. Res. Vet. Sci. doi:10.1016/j.rvsc.2008.12014.

Marinho M., Langoni H., Oliveira S.L., Carreira R., Perri S.H.V. \& Luzivoto M.C. 2003. Resposta humoral, recuperação bacteriana e lesões histológicas em camundongos geneticamente selecionados para bons e maus produtores de anticorpos e Balb/c, frente à infecção por Leptospira interrogans serovar icterohaemorrhagiae. Pesq. Vet. Bras. 23:5-12.
Maxie M.G. 1993. The urinary system, p.447-538. In: Jubb K.V.F., Kennedy P.C. \& Palmer N. (Eds), Pathology of Domestic Animals. $4^{\text {th }}$ ed. Academic Press, London.

Oliveira R.C., Freitas J.C., Silva F.G., Souza E.M., Delbem Á.C.B., Alves L.A., Muller E.E., Balarim M.S., Reis A.C.F., Batista T.N. \& Vasconcellos S.A. 2005. Diagnóstico laboratorial da leptospirose em um cão utilizando diferentes técnicas. Arqs Inst. Biológico, São Paulo, 72:111-113.

Plank R. \& Dean D. 2000. Overview of the epidemiology, microbiology and pathogenesis of Leptospira spp in humans. Microb. Infect. 2:1265-1276.

Rosetti C.A., Vanasco B.N., Pini N. \& Carfagnini J.C. 2004. Comparison of three diagnostic techniques for the detection of leptospires in the kidneys of wild house mice (Mus musculus). Pesq. Vet. Bras. 24:6-10.

Saglam Y.S., Temur A. \& Aslan A. 2003. Detection of leptospiral antigens in kidney and liver of cattle. Dtsch. Tierärztl. Wochenschr. 110:75-77.

Saglam Y.S., Yener Z., Temur A. \& Yalcin E. 2008. Immunohistochemical detection of leptospiral antigens in cases of naturally occurring abortions in sheep. Small Rumin. Res. 74:119-122.

Scanziani E., Sironi G. \& Mandelli G. 1989. Immunoperoxidase studies on leptospiral nephritis of swine. Vet. Pathol. 26:442-444.

Silva E.F., Brod C.S., Cerqueira G.M., Bourscheidt D., Seyffert N., Queiroz A., Santos C.S., Ko A.I. \& Dellagostin O.A. 2007. Isolation of Leptospira noguchii from sheep. Vet. Microbiol. 121:133-149.

Silva F.G., Freitas J.C., Anzai E.K., Hashimoto V.Y., Giraldi N., Delbem A.C.B., Bracarense A.P.F.R.L., Reis A.C.F. \& Vasconcellos S.A. 2005. Leptospires detection in kidney, liver and uterus of cows slaughtered in Paraná State, Brazil. Braz. J. Microbiol. 36:38-42.

Sitprija V., Pipatanagul V., Mertowidjojo K., Boonpuckanavig V. \& Boonpuckanavig S. 1980. Pathogenesis of renal disease in leptospirosis: clinical and experimental studies. Kidney Intern. 17:827-836.

Sitprija V., Losuwanrak T. \& Kanjanabuch T. 2003. Leptospiral nephropathy. Sem. Nephrol. 23:42-48.

Pirani C.L. 1993. Evaluation of kidney biopsy specimens, p.85-115. In: Tisher C.C. \& Brenner B.M. (Eds), Renal Pathology with Clinical and Functional Correlations. Vol.1. Lippincott Company, Philadelphia, PA.

Trap D. \& Garin-Bastuji B. 1988. Leptospirosis in sheep. B. Mens. Soc. Vet. Prat., France, 72:283-292.

Vasconcellos S.A. 2004. Laboratory diagnosis of leptospirosis in animals. Anais Eletrônicos Simpósio Internacional sobre Leptospira y Leptospirosis en las Americas, México. Acesso em 5 abr. 2004. Disponível em http:www.vps.fmvz.usp.br/mexico/anais.pdf

Zamora J., Riedemann S. \& Tadich N. 1999. A serological survey of leptospirosis in sheep in Chile. Revta Latinoamer. Microbiol., 41:73-76.

Yener Z. \& Keles H. 2001. Immunoperoxidase and histopathological examinations of leptospiral nephritis in cattle. J. Vet. Med. A. 48:441447. 